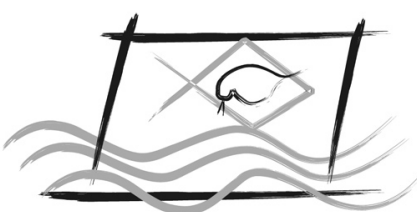

ECOTOX - BRASIL

\title{
Riscos à biota aquática pelo uso de tintas anti-incrustantes nos cascos de embarcações
}

\author{
T.L. MARTINS ${ }^{1,2} \&$ V.M.F. VARGaS ${ }^{1,3}$ \\ ${ }^{1}$ Curso de especialização em Toxicologia Aplicada, Instituto de Toxicologia Pontifícia Universidade Católica do Rio Grande do Sul - \\ PUCRS, Av. Ipiranga, 6681, 90619-900, Porto Alegre, RS, Brasil \\ ${ }^{2}$ Departamento de Fisiologia, Instituto de Ciências Básicas da Saúde, Universidade Federal do Rio Grande do Sul - UFRGS, Rua Sarmento \\ Leite, 500, 90050-170, Porto Alegre, RS, Brasil \\ ${ }^{3}$ Programa de Pesquisas Ambientais, Fundação Estadual de Proteção Ambiental Henrique Luis Roessler - FEPAM, Av. Dr. Salvador \\ França, 1707, 90690-000, Porto Alegre, RS, Brasil.
}

(Received March 01, 2010; Accept May 28, 2011)

\begin{abstract}
Resumo
Os cascos das embarcações estão constantemente sujeitos à bioincrustação, o que resulta na diminuição significativa da eficiência operacional, elevando os custos devido ao aumento no consumo de combustível. Dentre os diversos sistemas antiincrustantes desenvolvidos para contornar este problema, os que apresentam compostos organoestânicos em suas formulações tornaram-se o foco das discussões entre órgãos ambientais nas últimas décadas. Estes compostos são considerados uma ameaça à biota aquática em áreas com intensa atividade naval e podem agir como disruptores endócrinos em invertebrados. Após as restrições impostas para o uso de tintas à base de organoestanhos, outros biocidas vêm sendo utilizados. No entanto, tais produtos também apresentam efeitos tóxicos ao meio ambiente. Este artigo apresenta uma revisão da literatura relacionada aos riscos da exposição de organismos aquáticos aos compostos que constituem as tintas anti-incrustantes, assim como as alternativas propostas para substituir os produtos atualmente comercializados.
\end{abstract}

Palavras-chave: Bioincrustação, biota aquática, ecotoxicologia, embarcações, organoestanhos, tintas anti-incrustantes.

\section{Risks to aquatic biota by the use of antifouling paints}

\begin{abstract}
The ship hulls are constantly subject to marine biofouling, wich results in a significantly diminution in operational efficiency, rising the costs due to the increase of fuel consumption. From the antifouling systems developed to prevent this problem, those whom present organotin compounds in their formulations became the center of discussions among environmental organs in the last decades. These compounds are considered a threat to marine life in areas with intense naval activity and can act as endocrine disruptors in invertebrates. After restrictions imposed on the use of organotin antifouling paints, others biocides have been used. However, these products also have adverse effects on marine ecosystems. This article reviews the literature related to the risks of the exposure of aquatic organisms to antifouling paints compounds, as well as the alternatives proposed to replace the products yet commercialized.
\end{abstract}

Keywords: Antifouling paints, aquatic biota, bioincrustation, ecotoxicology, organotin, ship.

*Corresponding author: Vera Maria Ferrão Vargas; e-mail: vera.vargas@pq.cnpq.br 


\section{INTRODUÇÃO}

A incrustação biológica constitui um dos maiores problemas encontrados pelo homem em suas atividades no mar (Medeiros et al., 2007). Seu aparecimento provoca danos nas estruturas submersas e causa prejuízos econômicos, porque eleva o consumo de combustível no caso das embarcações, uma vez que a incrustação torna irregular a superfície dos cascos, aumentando o arrasto e reduzindo a velocidade.

$\mathrm{O}$ uso de tintas anti-incrustantes nos cascos das embarcações ajuda a evitar o estabelecimento e crescimento de algas, mexilhões e outros organismos marinhos. Por muitos anos, tintas à base de compostos orgânicos de estanho, tais como TBT (tributilestanho) e TPT (trifenilestanho), eram amplamente utilizadas para este fim. No entanto, a partir da década de 80 o uso passou a ser controlado devido ao seu potencial risco ao ecossistema aquático (Felizzola, 2005).

Estes compostos organoestânicos são considerados uma ameaça à vida marinha em áreas com intensa atividade naval e podem agir como disruptores endócrinos em invertebrados (Da Costa et al., 2008). Em algumas espécies de gastrópodes, baixas concentrações de TBT e/ou TPT são capazes de induzir alterações sexuais irreversíveis em fêmeas, um fenômeno conhecido como "imposex". Esta anormalidade é o resultado de um processo de masculinização, com o desenvolvimento de órgãos sexuais, tais como pênis e canal deferente, podendo resultar na deficiência da função reprodutiva, levando ao declínio da população ou ainda à extinção da espécie (Nakanishi, 2008; Horiguchi et al., 2006).

Diversos estudos têm sido desenvolvidos sobre a ocorrência e os efeitos desses compostos organometálicos, principalmente em países do hemisfério norte. No Brasil ainda são poucos os trabalhos que enfocam o problema, embora o litoral brasileiro represente cerca de $40 \%$ das regiões costeiras do Atlântico Sul. A maioria destes estudos se concentra nas regiões sudeste (Fernandez et al., 2002, 2005; Da Costa et al., 2008) e nordeste do país (Castro et al., 2000, 2004, 2005, 2008; Queiroz et al., 2007).

Com a proibição da presença de organoestânicos na formulação de tintas anti-incrustantes a partir da Convenção AFS da Organização Marítima Internacional (IMO), outros biocidas foram propostos em substituição a esses compostos, porém algumas destas substâncias também apresentam efeitos adversos ao meio ambiente.

O presente trabalho apresenta uma revisão, a partir da literatura disponível, acerca do histórico e das descobertas mais recentes em relação aos efeitos tóxicos dos compostos anti-incrustantes sobre a biota aquática, além de destacar as regulamentações vigentes, no Brasil e no mundo, referentes à aplicação destes produtos nos cascos das embarcações. Também serão discutidas algumas alternativas propostas para substituir os biocidas atualmente comercializados.

\section{HISTÓRICO}

Produtos anti-incrustantes são usados desde os tempos antigos, quando eram utilizadas substâncias naturais como cera, piche e betume para revestir os cascos dos navios, que eram feitos de madeira. Fenícios e Cartagineses parecem ter sido os primeiros a utilizarem o cobre para esse propósito (Almeida et al., 2007a).

Em 1625, uma receita letal combinando arsênio, cobre e goma em pó foi patenteada por William Beale como agente anti-incrustante (WHOI, 1952). Em meados do século XIX surgem as primeiras tintas desenvolvidas para esse fim, baseadas na ideia de dispersão de uma substância tóxica potente em um aglutinante polimérico (Almeida et al., 2007a). Nessa mesma época, o óxido cuproso passou a ser utilizado como biocida em tintas anti-incrustantes. No entanto, as tintas à base de cobre se tornavam ineficientes em menos de um ano e, portanto, biocidas mais efetivos foram necessários. Vários outros biocidas foram testados em tintas sendo os compostos organomercurosos e arsenicais utilizados até cerca de 1970 para aumentar a eficiência das tintas à base de óxido cuproso (Godoi et al., 2003).

Em 1961, foi desenvolvida a primeira tinta incorporando um composto organoestânico como biocida. Devido à sua grande eficácia como agente anti-incrustante, o uso destas tintas aumentou drasticamente nas décadas seguintes (Tolosa et al., 1996). Até os anos 90, o consumo mundial destes produtos cresceu de 1.500 para 50.000 toneladas ano $^{-1}$ (Santalla, 2008).

O primeiro estudo sistemático sobre organoestanhos foi realizado por Edward Franckland em 1853, tendo sintetizado o di-iodeto de dietilestanho e, em 1859, o tetraetilestanho. Estes compostos mantiveram-se por muito tempo apenas sob interesse científico, sendo sua utilização como biocidas proposta somente por volta de 1950, a partir de um estudo conduzido pelo Conselho Internacional de Pesquisas sobre Tintas, no Instituto de Química Orgânica, em Utrecht, sobre a ação destes compostos em fungos e bactérias, organismos marinhos, vermes parasitas, caramujos aquáticos e insetos. As propriedades biocidas dos compostos trialquilestânicos e triarilestânicos foram então descobertas e passaram a ser exploradas comercialmente (Godoi et al., 2003; Santalla, 2008). Entretanto, estes produtos, principalmente aqueles contendo tributilestanho (TBT), também alcançaram notoriedade como compostos altamente tóxicos, afetando inclusive organismos não-alvo, tais como peixes, bivalves, gastrópodes, crustáceos e algas.

O problema chamou a atenção do Comitê de Proteção do Ambiente Marinho (MEPC) da Organização Marítima Internacional (IMO), interessada na segurança da navegação e prevenção da poluição marinha. Como resultado, em 1990, a IMO adotou uma resolução recomendando os governos a adotarem medidas para eliminar as tintas anti-incrustantes à base de TBT. Em 1999, a IMO adotou uma resolução que serviu como instrumento mundial de comunicação do MEPC sobre os efeitos nocivos dos sistemas anti-incrustantes utilizados em embarcações. A resolução se referia à 
proibição global da aplicação de compostos organoestânicos em embarcações a partir de $1^{\circ}$ de janeiro de 2003 , sendo o prazo limite para a circulação de navios contendo esses compostos aplicados em seus cascos estabelecido a partir de $1^{\circ}$ de janeiro de 2008 (Dos Santos, 2008).

\section{BIOINCRUSTAÇÃO}

Estruturas marítimas como plataformas, molhes e cascos de embarcações estão sujeitos ao processo de bioincrustação. Nesse processo quando um substrato químico inerte é imerso na água do mar ocorre uma acumulação imediata de resíduos de carbono adsorvidos na superfície molhada. As forças que promovem a adsorção e o condicionamento desta superfície incluem interações eletrostáticas e forças de Van der Waal. Microorganismos pioneiros se aderem à estrutura formando um biofilme. Bactérias e outros organismos colonizadores secretam uma substância extracelular polimérica (EPS) para envolver e ancorar os mesmos ao substrato por meio da alteração da composição química do local, estimulando o crescimento e estabelecimento de outros macroorganismos (Chambers et al., 2006).

O biofilme gerado é uma massa de microorganismos e suas EPS formando uma matriz gelatinosa, provendo interações enzimáticas, transferência de nutrientes, proteção ao estresse ambiental e aumento da resistência a biocidas (Chambers et al., 2006).

As técnicas de adesão empregadas pelos organismos incrustantes são diversas e podem ser constituídas por dois processos: a adesão temporária e a adesão permanente. A primeira é utilizada durante a exploração da superfície do substrato pelo organismo, em um estágio móvel do seu ciclo de vida. Uma vez encontrado o local apropriado, o indivíduo se fixa e se adere permanentemente (Chambers et al., 2006; Khandeparker \& Anil, 2007).

A adesão e o estabelecimento de espécies ao substrato é um aspecto importante da bioincrustação, pois se este processo pode ser prevenido, a incrustação pode ser controlada.

A incrustação biológica a que os cascos dos navios imersos no mar estão sujeitos resulta na diminuição significativa da eficiência operacional com conseqüente aumento dos custos, devido principalmente ao aumento no consumo de combustível. A incrustação de $10 \mu \mathrm{m}$ no casco de um navio pode significar um aumento de 0,3 a $1 \%$ no consumo de combustível (Champ \& Lowenstein, 1987; Santalla, 2008).

Existem diferentes tipos de tintas anti-incrustantes (Hoch, 2001; Dos Santos, 2008; Almeida et al., 2007b; Takahashi, 2009):

- Tintas de Livre Associação ("free-association"): o biocida é fisicamente misturado na matriz da tinta e é liberado para o ambiente aquático por difusão, com duração média de dois anos.

- Tintas de Autopolimento ("self-polishing"): um componente tóxico é quimicamente ligado a um polímero causando um atraso na liberação do agente biocida para a água e que possui efetividade por cerca de cinco a sete anos.

- Tintas Ablativas/Erodíveis ("ablative/hydration"): consistem numa grande proporção de ligantes de secagem física, não tóxicos e solúveis em água do mar, combinados com ingredientes poliméricos capazes de controlar, por processos físicos, a velocidade relativa dos mecanismos de dissolução. Em contato com a água, os biocidas dissolvem-se juntamente com o ligante solúvel, sendo os ingredientes controladores do processo de dissolução "lavados" da superfície. Possuem efetividade superior a três anos.

- Tintas Isentas de Biocidas ("biocide-free"): compostas por silicones ou fluoropolímeros. São hidrofóbicas e possuem superfícies ultra-lisas, que asseguram muito baixa fricção, de modo que os organismos incrustantes são incapazes de se fixar e aderir a elas. Contudo, ao final de três anos de exposição em água do mar, apenas conseguem evitar a incrustação em cerca de $20 \%$, sendo eficientes somente em navios de alta velocidade ( $\geq 22$ nós).

\section{ORGANOESTANHOS}

Os compostos organoestânicos são substâncias químicas que possuem ao menos uma ligação entre carbono e estanho $\left(\mathrm{Sn}^{4+}\right)$. Apresentam a fórmula geral $\mathrm{R}_{(4-n)} \mathrm{SnX}_{n}$, onde o R é um grupo alquil ou aril, que se liga covalentemente com o átomo de estanho, X representa uma espécie aniônica, como cloreto, óxido, hidróxido ou outro grupo funcional, e $n$ pode variar de 0 a 3 (Rüdel, 2003; Godoi et al., 2003; Santalla, 2008).

Os organoestanhos possuem uma série de propriedades e aplicações, dependendo do número de ligações estanhocarbono. Os compostos tetraorganoestânicos não possuem atividadebiológicasignificativa esua maioraplicação comercial é como precursor para outros compostos organoestânicos. A atividade biológica máxima ocorre nos derivados trivalentes, sendo estes compostos utilizados comercialmente como biocidas em várias áreas (Santalla, 2008; Felizzola, 2005).

Dentre todas as aplicações comerciais, a maior entrada de organoestanhos no ambiente aquático é atribuída ao uso de tintas anti-incrustantes, baseadas nos compostos com atividade biológica máxima (TBT e TPT) agindo como inibidores da incrustação biológica (Hoch, 2001; Rüdel, 2003; Godoi et al., 2003). A grande maioria dos trabalhos indica uma maior concentração dos mesmos em áreas costeiras, próximos a portos, onde os navios permanecem durante dias esperando para serem carregados, ou em docas e marinas, onde são realizadas as manutenções das embarcações (Dos Santos, 2008).

Fora o uso de tintas anti-incrustantes, os organoestanhos podem chegar ao ambiente a partir de uma variedade de aplicações industriais e agrícolas (Hoch, 2001; Gadd, 2000). A grande maioria das pesquisas têm sido restritas à contaminação por TBT e TPT, por estes compostos entrarem diretamente no ambiente através de biocidas industriais. Porém, evidências mostram que efluentes municipais e industriais também podem 
ser importantes fontes de organoestanhos para o ambiente aquático (Hoch, 2001). Isso devido à utilização de derivados organoestânicos mono e dissubstituídos como estabilizadores de plásticos e catalisadores (Rüdel, 2003). Os organoestanhos ainda podem ser encontrados em embalagens de alimentos, reservatórios de água, espumas de poliuretano, biocidas agrícolas, desinfetantes, equipamentos elétricos e em muitos outros produtos do consumo humano (Dos Santos, 2008).

No ambiente aquático, os componentes triorganoestânicos possuem baixa solubilidade e mobilidade, sendo facilmente adsorvidos no material particulado em suspensão (Hoch, 2001). De acordo com Gadd (2000), aproximadamente 95\% do TBT presente na coluna d'água está ligado ao material em suspensão, incluindo o plâncton, enquanto o restante está amplamente associado à matéria orgânica dissolvida e a ligantes orgânicos e inorgânicos. Assim, esta adsorção pode ser considerada um importante processo de destino do TBT nos sistemas aquáticos (Hoch, 2001). O mesmo acontece para os compostos trifenilestânicos que têm demonstrado baixa mobilidade em água e forte ligação a sedimentos no ambiente aquático (Ceulemans et al., 1998; Dos Santos, 2008).

A razão sorção/dessorção do TBT com o sedimento pode ser influenciada por mudanças no $\mathrm{pH}$ e na salinidade do ambiente. Em razão da reversibilidade da adsorção do TBT a essa matriz, a mesma estando contaminada pode agir como uma fonte destes contaminantes para o ambiente em longo prazo (Antizar-Ladislau, 2008). Isso porque uma vez nos sedimentos, esses compostos podem ser novamente liberados para a coluna d'água através de processos de ressuspensão, aumentando os riscos ecotoxicológicos para os organismos presentes no meio (Hoch, 2001).

A degradação dos compostos organoestânicos ocorre por meio de processos bióticos e abióticos. A transformação é similar em ambos os casos (TBT e TPT) e leva, via desalquilação ou desarilação, à liberação de estanho inorgânico $\left(\mathrm{TTBT} \rightarrow \mathrm{TBT}^{+} \rightarrow \mathrm{DBT}^{2+} \rightarrow \mathrm{MBT}^{3+} \rightarrow \mathrm{Sn}^{4+}\right)$. O único processo de degradação abiótica de TBT que se destaca é a fotólise, uma vez que a hidrólise das ligações estanho-carbono não é relevante em valores de $\mathrm{pH}$ e temperaturas ambientais (Rüdel, 2003; Maguire et al., 1986). Quase toda radiação ultravioleta emitida pelo sol, com comprimento de onda menor que $290 \mathrm{~nm}$, é absorvida pela camada de ozônio. Entretanto, a luz de $290 \mathrm{~nm}$ possui uma energia de aproximadamente $300 \mathrm{~kJ}$ $\mathrm{mol}^{-1}$, o suficiente para romper as ligações estanho-carbono, que requerem uma energia de dissociação entre 190-200kJ mol $^{-1}$ (Omae, 2006; Hoch, 2001).

A degradação biótica por microorganismos é a principal forma de decomposição destes compostos (Alzieu, 2000; Omae, 2006). A meia-vida do TBT neste processo, em águas doces e salgadas, é de seis dias até muitas semanas, mas a biodegradação pode ser muito mais lenta em sedimentos, principalmente em condições anaeróbias, cuja persistência está estimada entre dois anos até várias décadas (Antizar-Ladislau, 2008; Rüdel, 2003). Em alguns locais, o TBT tem sido encontrado em concentrações tão elevadas que a sua degradação biológica pode ser inibida, em decorrência da elevada toxicidade para esses organismos (Ceulemans et al., 1998).

\section{ECOTOXICOLOGIA}

O potencial tóxico dos compostos organoestânicos para a biota aquática está bem documentado, principalmente quando se trata dos efeitos tóxicos destes produtos sobre o desenvolvimento sexual e reprodutivo em invertebrados. Dentre estes animais, os moluscos se enquadram como o principal objeto de estudo das pesquisas, refletindo sua importância ecológica, comercial e sua utilização como bioindicadores da poluição aquática (Ketata et al., 2008).

A sobreposição de caracteres sexuais masculinos, tais como pênis e canal deferente, em fêmeas de moluscos, é um dos efeitos mais estudados. Esse fenômeno, também conhecido como "imposex", é uma manifestação evidente de alterações endócrinas induzidas pela exposição aos organoestanhos.

As primeiras ocorrências de imposex foram registradas no início dos anos 70 em Nucella lapillus (Blaber, 1970), Ilyanassa obsoleta (Smith, 1971), Thais emarginata (Houston, 1971) e Ocenebra erinacea (Féral, 1974), mas este fenômeno é mais abrangente, afetando mais de 200 espécies em diferentes regiões do mundo (Bigatti et al., 2009). No Brasil já foram registrados casos em regiões costeiras do nordeste (Castro et al., 2000, 2004, 2005, 2008; Queiroz et al., 2007), sudeste (Fernandez et al., 2002, 2005; Da Costa et al., 2008) e sul do país (Castro et al., 2007).

A intensidade da virilização em fêmeas é dependente da concentração de TBT ou TPT no meio, podendo levar à esterilidade do animal. Os efeitos têm conseqüências diretas na função reprodutiva, devido ao bloqueio da abertura do oviduto pelo desenvolvimento do canal deferente, impedindo a postura de ovos; ou a espermatogênese ovariana, levando ao declínio da população; ou ainda à extinção da espécie em locais severamente contaminados (Nishikawa et al., 2004; Ketata et al., 2008; Horiguchi et al., 2006).

Contudo, em um estudo em que fêmeas sem imposex do molusco Stramonita haemastoma foram transplantadas para uma marina com fluxo intenso de embarcações no nordeste brasileiro, Queiroz et al. (2007) constataram uma alta incidência de afalia em fêmeas que desenvolveram a anomalia. Os autores propuseram que esse subdesenvolvimento de caracteres sexuais masculinos possa ser causado pela presença de uma alteração genética na população, a Síndrome de Dumpton. Segundo Gibbs (1993), esta síndrome pode conferir uma vantagem adaptativa para os gastrópodes em locais contaminados com compostos organoestânicos, uma vez que a masculinização em fêmeas é atenuada, tornando possível a sobrevivência nessas áreas.

Embora haja uma ligação entre a indução de imposex e a exposição aos biocidas organoestânicos, o mecanismo exato pelo qual ele ocorre ainda não foi esclarecido (Lyssimachou et al., 2008). Algumas hipóteses especulam que estes compostos agem como inibidores específicos da enzima aromatase do 
citocromo P450 (Nakanishi, 2008). A inibição da atividade desta enzima, responsável pela conversão de testosterona em 17ß-estradiol, resulta em um acúmulo de testosterona nas fêmeas, induzindo o desenvolvimento dos caracteres sexuais masculinos (Leung et al., 2006). Este fenômeno também já foi observado em peixes (Shimasaki et al., 2003; McAllister \& Kime, 2003). Entretanto, sugere-se que este mecanismo seja ainda mais complexo (Oberdöster et al., 2005).

Oberdörster et al. (2005) constataram que os níveis endógenos do neuropeptídeo APGWamide, que está relacionado com o comportamento reprodutivo e a eversão peniana em algumas espécies de moluscos, eram elevados em fêmeas do gastrópode I. obsoleta quando a indução do imposex era feita a partir de TBT. Porém, esse efeito não era observado quando esta alteração endócrina era estimulada pela testosterona.

Em outro estudo, Nishikawa et al. (2004) demonstraram que em Thais clavigera o TBT interage com receptor de retinóides X (RXR) com uma afinidade maior que seu ligante natural, o ácido retinóico 9-cis. É possível que esse composto organoestânico se ligue aos receptores da superfamília dos hormônios esteróides (como o RXR) e promova a transcrição gênica de moléculas que sinalizem o desenvolvimento de órgãos sexuais, entre elas o APGWamide (Oberdöster et al., 2005).

Em vertebrados, organoestânicos podem agir como agonistas de RXR e de PPAR $\gamma$ (receptor ativado por proliferadores de peroxissoma), receptores nucleares que desempenham um papel fundamental na homeostase lipídica e na adipogênese. Camundongos expostos in utero ao TBT mostraram um elevado acúmulo de lipídios em depósitos de gordura, no fígado e testículos de neonatos e aumento da massa adiposa em epidídimo de adultos (Grün et al, 2006). Em rãs Xenopus laevis, o aparecimento de adipócitos ectópicos ao redor de tecidos gonadais foram observados após a exposição a esses biocidas (Grün et al, 2006). Esses resultados sugerem que os compostos à base de estanho podem agir como fatores "obesogênicos", aumentando a incidência de obesidade ou outras desordens metabólicas relacionadas.

O acúmulo de compostos organoestânicos na biota é influenciada pela presença de proteínas específicas, como a glutationa, prevalente no fígado e rins, e as alfa-queratinas, que são os principais componentes estruturais de cabelos, unhas e penas. Esses compostos podem se ligar aos grupos sulfidrila e amina destas proteínas (Kannan \& Falandysz, 1997).

Além de peixes, mamíferos marinhos de níveis tróficos mais elevados, como golfinhos e toninhas, acumulam consideráveis concentrações de organoestânicos no fígado. Da mesma forma, aves que se alimentam de peixes contaminados acumulam níveis significativos destes elementos em vários tecidos e órgãos, principalmente nas penas, que concentram cerca de $20-30 \%$ de toda carga de organoestânicos ingerida (Kannan \& Falandysz, 1997).

Considerando os efeitos tóxicos à exposição de compostos organoestânicos, o fato destes biocidas bioacumularem na cadeia trófica gera preocupações quanto aos riscos do consumo humano de alimentos contaminados, como peixes e frutos do mar.

A avaliação dos riscos à saúde humana baseia-se principalmente em estudos experimentais com animais. A partir destas pesquisas foi proposto um espectro de potenciais efeitos adversos da exposição crônica, que incluem: imunossupressão, endocrinopatias, alterações enzimáticas e metabólicas, discrasias sanguíneas, distúrbios cardiovasculares, pulmonares e gastrointestinais, bioacumulação renal e hepática, e possível atividade carcinogênica (Nakanishi, 2008). Ainda foi estabelecido um valor de Ingestão Diária Tolerável (TDI) para TBT de $0,25 \mu \mathrm{g}$ $\mathrm{x}$ kg de massa corporal ${ }^{-1} \mathrm{x} \mathrm{dia}^{-1}$, adotado pela Organização Mundial de Saúde (OMS) (Antizar-Ladislau, 2008).

Em um estudo in vitro com linfócitos natural killer humanos (a primeira linha de defesa imune contra tumores e infecções virais), Whalen et al. (1999, 2000) demonstraram que o TBT e o TPT são capazes de diminuir a ação citotóxica desses linfócitos sobre células tumorais, podendo aumentar o risco de desenvolvimento de câncer. Heidrich et al. (2001) observaram que esses compostos também podem agir inibindo a enzima aromatase humana.

\section{LEGISLAÇ̃̃̃O}

As primeiras ações regulatórias para o uso de compostos organoestânicos foram adotadas na França em 1982, seguida pela Inglaterra em 1985. Essas ações foram baseadas em uma avaliação do impacto do TBT sobre ostras da espécie Crassostrea gigas, comercialmente cultivadas na baia de Arcachon, na costa atlântica francesa. Entre 1975 e 1982, foi constatado um decréscimo significativo na abundância destes animais e a ocorrência de má formação das conchas, o que raramente era observado antes, aumentou, afetando de 80 a $100 \%$ da população (Felizzola, 2005; Alzieu, 2000). Estimase que a perda financeira da ostreicultura na região tenha sido de aproximadamente 147 milhões de dólares (Alzieu, 2000).

Em 1982, os franceses baniram a aplicação de tintas antiincrustantes contendo TBT em cascos de embarcações menores de 25 metros. Após alguns anos, os pesquisadores franceses notaram uma diminuição significativa nas concentrações de compostos organoestânicos nas águas da baía de Arcachon e um aumento na produção de ostras (Felizzola, 2005).

A partir de 1988 o assunto tomou importância na Organização Marítima Internacional (IMO), que formou grupos técnicos para estudar os efeitos dos anti-incrustantes sobre o meio ambiente marinho e sobre a saúde humana (NORMAM-23/DPC, 2007).

Como resultado dos impactos ecotoxicológicos do TBT observados, em novembro de 1999 a IMO adotou a Resolução A.895(21), recomendando aos países membros a adoção de medidas destinadas a restringir o uso dos anti-incrustantes à base de TBT. Posteriormente, em 2001, com a continuidade das pesquisas, foi aprovada a Convenção Internacional sobre Controle de Sistemas Anti-incrustantes Danosos em 
Embarcações - Convenção AFS, estabelecendo que os compostos organoestânicos que atuam como biocidas em sistemas anti-incrustantes deveriam ser gradativamente eliminados até $1^{\circ}$ de janeiro de 2008. O Brasil assinou esta convenção em 13 de novembro de 2002 (NORMAM-23/ DPC, 2007).

Em novembro de 2007, entrou em vigor no Brasil a Portaria 76 da Diretoria de Portos e Costas, da Marinha do Brasil, que aprova as Normas da Autoridade Marítima para o Controle de Sistemas Anti-incrustantes Danosos em Embarcações - NORMAM-23/DPC. Estas normas têm como propósito estabelecer procedimentos referentes ao controle do uso de sistemas anti-incrustantes danosos ao meio ambiente marinho ou à saúde humana. Aplicam-se às embarcações brasileiras, cujos cascos necessitam ser pintados com sistemas antiincrustantes, e às embarcações estrangeiras que atracarem no Brasil para pintura dos cascos ou que estiverem afretadas em regime de AIT (Atestado de Inscrição Temporária).

\section{OUTROS ANTI-INCRUSTANTES}

\section{Cobre}

O cobre é um biocida que tem sido utilizado a mais de 200 anos como um eficiente agente anti-incrustante (ICOMIA, 2006). Uma das vantagens da utilização de tintas baseadas em cobre é o fato de ser um elemento que ocorre naturalmente no ambiente. As concentrações de cobre variam entre 0,03 e $0,23 \mu \mathrm{g} \mathrm{L}^{-1}$ em águas marinhas e entre 0,2 e $30 \mu \mathrm{g} \mathrm{L} \mathrm{L}^{-1} \mathrm{em}$ águas doces. Também, em pequenas quantidades, o cobre é um micronutriente essencial para os seres vivos (Srinavasan \& Swain, 2007).

Nos últimos dez anos surgiram preocupações quanto aos efeitos do cobre sobre o ambiente marinho. Altos níveis deste metal foram detectados em áreas de intensa operação naval. Isto se deve, em parte, ao aumento do número de embarcações que adotaram tintas anti-incrustantes tendo o cobre como biocida principal, geralmente sob a forma de óxido cuproso $\left(\mathrm{Cu}_{2} \mathrm{O}\right)$ ou tiocianato de cobre (CuCHNS), em substituição às compostas por TBT, cuja aplicação agora é regulada (Srinavasan \& Swain, 2007). Zinco inorgânico, como o óxido ou acrilato de zinco, é utilizado frequentemente combinado ao cobre para aumentar a toxicidade da formulação ou facilitar o processo de lixiviação (Watermann et al., 2005).

$\mathrm{O}$ potencial tóxico dessas tintas à biota marinha já foi estudado e constatado em diversos trabalhos (ReicheltBrushett \& Harrison, 2000; Saphier \& Hoffmann, 2005; Johnson et al., 2007). Em 2003, Katranitsas et al. (2003) verificaram uma inibição na atividade das enzimas $\mathrm{Na}^{+} /$ $\mathrm{K}^{+}$-ATPase e $\mathrm{Mg}^{2+}$-ATPase em camarões Artemia nauplii expostos a placas revestidas com tintas à base de cobre. $\mathrm{O}$ efeito tóxico destes produtos se deve à liberação contínua de íons $\mathrm{Cu}^{+}$na água. Estes íons são rapidamente oxidados em íons cúpricos $\left(\mathrm{Cu}^{+2}\right)$, que são a forma prevalente de cobre dissolvido em ambiente marinho. Quando os íons $\mathrm{Cu}^{+2}$ entram nas células, são reduzidos novamente à $\mathrm{Cu}^{+}$, que possui grande afinidade com grupos sulfidrilos (-SH), constituintes de enzimas ATPases. A ligação de íons $\mathrm{Cu}^{+}$a estes grupos promove uma mudança estrutural que impede o transporte iônico, inativando a enzima e, consequentemente, causando um desequilíbrio na osmorregulação.

A maioria das tintas anti-incrustantes à base de cobre comercializadas contém co-biocidas que aumentam a eficácia destes produtos na prevenção da bioincrustação, tais como Irgarol $^{\mathbb{R}}$ 1051, ZPT ${ }^{\circledR}$, Diuron ${ }^{\circledR}$ e Sea-Nine ${ }^{\circledR} 211$. Alguns destes co-biocidas também apresentam efeitos adversos ao meio ambiente.

\section{Irgarol $^{\circledR} 1051$}

Em meados da década de 80, tintas anti-incrustantes contendo Irgarol $^{\circledR} 1051$, um herbicida do tipo triazina, foram introduzidas na Europa quando surgiram restrições ao uso de tintas à base de compostos organoestânicos (Hall et al., 2009).

Esse composto é pouco solúvel e moderadamente lipofílico usado em combinação com o cobre para controlar a incrustação nos cascos das embarcações. $\mathrm{O} \operatorname{Irgarol}{ }^{\circledR}$, como outros herbicidas triazinas, age bloqueando o transporte de elétrons na fotossíntese, especificamente inibindo o fotossistema II, um sistema de transferência de energia. A inibição deste sistema reduz a captação de $\mathrm{CO}_{2}$ pela planta e, consequentemente a produção de carboidratos, levando o organismo a um colapso energético (Hall et al., 2009). Estes efeitos podem ocorrer em concentrações tão baixas quanto $1 \mu \mathrm{g} \mathrm{L}^{-1}$ (Tolosa et al., 1996).

As preocupações quanto ao uso deste produto aumentaram após as constatações de altas concentrações na região costeira ao sul da França (até 1.700ng L ${ }^{-1}$ ) e sudeste da Inglaterra (até 1421ng $\left.\mathrm{L}^{-1}\right)$ (Tolosa et al., 1996; Konstantinou \& Albanis, 2004).

\section{Diuron $^{\circledR}$}

Diuron $^{\circledR}$ é um herbicida (uréia substituída) que, assim como o Irgarol ${ }^{\circledR} 1051$, age inibindo o fotossistema II de plantas e microorganismos fotossintetizantes, porém é mais persistente no ambiente que este, já que é consideravelmente estável à hidrólise e à radiação solar (Konstantinou \& Albanis, 2004; Okamura, 2002).

Este composto já foi determinado em concentrações superiores às do $\operatorname{Irgarol}^{\circledR} \mathrm{e}$ de outros biocidas em ambientes aquáticos. A presença ubíqua do Diuron ${ }^{\circledR}$ se deve ao seu emprego freqüente na composição de tintas anti-incrustantes, assim como sua ampla utilização em outras áreas de aplicação, principalmente no controle de ervas daninhas em atividades agrícolas (Konstantinou \& Albanis, 2004). Sugere-se que a contaminação por este herbicida em áreas costeiras e estuarinas seja suplementada pela drenagem de áreas onde ocorrem estas atividades.

\section{Sea-nine ${ }^{\circledR} 211$}

Sea-nine ${ }^{\circledR} 211$ (4,5-dichloro-2-n-octyl-4-isothiazolinone), também conhecido como Kathon 5287, C-9 e DCOIT, foi 
introduzido especificamente como um anti-incrustante em 1996. É utilizado como o principal componente ou ativador nas tintas anti-incrustantes comercializadas, tendo sua importância ambiental sido reconhecida pela EPA (Agência de Proteção Ambiental dos EUA) com o prêmio "Desafios em Química Verde" (Konstantinou \& Albanis, 2004). Entretanto, estudos recentes verificaram que este produto é ainda mais tóxico que outros biocidas, como $\operatorname{Irgarol}^{\mathbb{R}} \mathrm{e}$ Diuron $^{\circledR}$ (Konstantinou \& Albanis, 2004; Kobayashi \& Okamura, 2002; Cima et al., 2008).

A concentração ambiental máxima passível de causar efeitos adversos em espécies não-alvo foi previamente estabelecida como sendo 63ng L-1 (Shade et al., 1993). Por outro lado, Kobayahi e Okamura (2002), estudando os efeitos do Sea-nine ${ }^{\circledR}$ sobre o desenvolvimento de ouriços-do-mar, constataram que a concentração máxima deste composto sem apresentar efeitos para estes animais é de apenas $1 \mathrm{fg} \mathrm{L}^{-1}$.

A meia-vida de Sea-nine em soluções aquosas em pH 5, 7 e 9 é de $216 \mathrm{~h},>720 \mathrm{~h}$ e $288 \mathrm{~h}$, respectivamente (Shade et al., 1993), mas é rapidamente degradado por microorganismos, com meia-vida menor que $1 \mathrm{~h}$ em meio aquático e cerca de $24 \mathrm{~h}$ no sedimento, independente da presença de oxigênio (Jacobson \& Willingham, 2000). Uma vez degradado, seus metabólitos são até 100.000 vezes menos tóxicos que o composto original (Jacobson \& Williams, 2000).

\section{Clorotalonil}

Clorotalonil é um composto halógeno aromático e está presente na formulação de tintas anti-incrustantes, principalmente como biocida ativador. Porém, ao contrário do Sea-nine ${ }^{\circledR} 211$, é amplamente utilizado como fungicida na agricultura (Cima et al., 2008). Por essa razão, sua presença em águas costeiras é devida, em parte, à lixiviação do solo pela drenagem das águas de áreas agrícolas.

Foi comercialmente introduzido em 1969 como um pesticida de uso geral, classificado pela EPA como produto moderadamente tóxico. Sabendo-se de seus efeitos adversos na reprodução de peixes de água-doce, foi reconsiderado pelo seu potencial tóxico ao meio ambiente e à saúde humana. Desde 2002 é incluído na lista de substâncias carcinógenas pela EPA. Vários países já regulamentaram seu uso, mas apenas a Suécia baniu a utilização deste composto em qualquer tipo de aplicação.

Dados de testes de toxicidade aguda em algumas espécies de peixes mostraram que os valores para $\mathrm{LC}_{50}(96 \mathrm{~h})$ variam entre 16,3 e $52 \mu \mathrm{g} \mathrm{L}^{-1}$. Entretanto, os organismos marinhos mais sensíveis ao clorotalonil são as ostras da espécie Crassostrea virginica, com valores de $\mathrm{EC}_{50}$ de $7,3 \mu \mathrm{g} \mathrm{L} \mathrm{L}^{-1}$ (Voulvoulis et al., 2000; Konstantinou \& Albanis, 2004).

\section{Diclofluanida}

A diclofluanida é um biocida utilizado na formulação de tintas anti-incrustantes, também empregado na preservação de madeiras. Este composto é muito menos solúvel em água que o Irgarol ${ }^{\circledR} 1051$, porém se liga mais fortemente ao sedimento comparado ao $\operatorname{Irgarol}^{\circledR}$, clorotalonil e Diuron ${ }^{\circledR}$ (Voulvoulis et al., 2000).

Este biocida não parece ser persistente no ambiente marinho, visto que ensaios laboratoriais indicam uma meia-vida variando entre poucas horas até poucos dias no sedimento e água do mar, respectivamente (Parks et al., 2010; Thomas, 2001). Os principais metabólitos originados a partir da fotodegradação, hidrólise e degradação anaeróbia são DMSA ( $N$ '-dimethyl$N$-phenyl-sulphamide), $n$-dichlorofluomethylthio-aniline e anilina (Konstantinou \& Albanis, 2004).

Testes de toxicidade aguda utilizando trutas arco-íris (Oncorchyncus mykiss) mostraram valores para $\mathrm{LC}_{50}(96 \mathrm{~h}) \mathrm{de}$ $0,01 \mathrm{mg} \mathrm{L}^{-1}$ para diclofluanida e maiores que $100 \mathrm{mg} \mathrm{L}^{-1}$ para DMSA, indicando que a diclofluanida é muito mais tóxica aos organismos aquáticos em comparação ao seu metabólito (Hamwijk et al., 2005).

\section{Zinco Piritiona}

O biocida zinco piritiona (ZPT) foi introduzido em 1991 como um substituto do TBT em tintas anti-incrustantes. Este composto também é conhecido por sua ação bactericida e fungicida em xampus anticaspa e outros produtos cosméticos (Maraldo \& Dahllöf, 2004).

ZPT pode interagir com íons metálicos livres na água do mar, liberando zinco e assumindo íons como manganês, ferro e cobre (Turley et al., 2000; Konstantinou \& Albanis, 2004; Maraldo \& Dahllöf, 2004). A fotólise e a biodegradação deste composto são muito rápidas (meias-vidas menores que $1 \mathrm{~h} \mathrm{e}$ $2 \mathrm{~h}$, respectivamente), sendo a fotodegradação o processo mais eficaz.

Dado que o ZPT degrada rapidamente na coluna d'água, ou é adsorvido no sedimento, em longo prazo é o zinco que proporciona os riscos ambientais mais significativos (Konstantinou \& Albanis, 2004). Estudos com culturas em suspensão de células de peixe e ovos e embriões de ouriçodo-mar demonstraram que este produto é mais tóxico que o Irgarol $^{\circledR}$ 1051, Diuron ${ }^{\circledR}$ e Sea-Nine ${ }^{\circledR} 211$ (Okamura et al., 2002; Kobayashi \& Okamura, 2002).

\section{Ziram $^{\circledR}$ e Zineb ${ }^{\circledR}$}

Ziram $^{\circledR}$ (zinco bis-dimetilditiocarbamato) e Zineb ${ }^{\circledR}$ (zinco etileno-1,2-bis-ditiocarbamato) são conhecidos fungicidas ditiocarbamatos (DTC) usados no controle de doenças em cultivos de frutos e hortaliças, assim como na composição de tintas anti-incrustantes. Os principais metabólitos destes compostos são o dissulfeto de carbono $\left(\mathrm{CS}_{2}\right)$ e a etilenotiouréia (ETU), respectivamente (Van Wezel \& Van Vlaardingen, 2004; Agarwal et al., 2005).

Testes de toxicidade aguda com organismos aquáticos mostraram valores para $\mathrm{LC}_{50}(96 \mathrm{~h})$ de $1,9 \mathrm{mg} \mathrm{L}^{-1}$ para trutas arco-íris expostas ao Ziram ${ }^{\circledR}$ (Bayer CropScience, 2008) e de $2 \mathrm{mg} \mathrm{L}^{-1}$ e $6-8 \mathrm{mg} \mathrm{L}^{-1}$ para percas e carpas expostas ao Zineb ${ }^{\circledR}$, 
respectivamente (UCP, 2008). Os valores de $\mathrm{LD}_{50}$ oral para ratos expostos a estes ditiocarbamatos são de $1400 \mathrm{mg} \mathrm{Kg}^{-1}$ para Ziram $^{\circledR}$ e $7600 \mathrm{mg} \mathrm{Kg}^{-1}$ para Zineb ${ }^{\circledR}$ (Agarwal et al., 2005).

Em um estudo com cultura de células mesencefálicas de ratos, Chou et al. (2008) demonstraram que o Ziram ${ }^{\circledR}$ aumentou a expressão de $\alpha$-sinucleína, um gene identificado como causador da mutação que acarreta o Mal de Parkinson, além de induzir dano seletivo em células dopaminérgicas e inibir o sistema ubiquitina-proteassoma, interferindo com a atividade da enzima E1, ativadora da ubiquitina.

Outros estudos também demonstraram a potencial atividade mutagênica do Zineb ${ }^{\circledR}$. Já se constatou a capacidade deste produto em induzir mutações pontuais, aberrações cromossômicas em linfócitos de trabalhadores expostos ocupacionalmente em atividades agrícolas, atraso no ciclo celular de linfócitos humanos e células de ovário de hamster chinês, e geração de espécies reativas de oxigênio (Soloneski et al., 2003).

\section{ALTERNATIVAS}

A busca por alternativas a tintas anti-incrustantes contendo TBT tem levado diversos pesquisadores a concentrar esforços no desenvolvimento de substâncias menos danosas à biota marinha (Medeiros et al., 2007).

Produtos naturais de origem marinha podem ser utilizados para substituir os componentes químicos usualmente empregados nas tintas anti-incrustantes. Muitos animais sésseis desenvolvem-se livres da incrustação por outros organismos graças à produção de metabólitos que apresentam propriedades anti-incrustantes (Burgess et al., 2003). Esse sistema de defesa é, provavelmente, uma resposta evolutiva às desvantagens ecológicas impostas pela epibiose, particularmente em organismos fotossintetizantes (Da Gama et al., 2008).

As macroalgas marinhas são conhecidas por produzir cerca de 3600 metabólitos secundários, muitos dos quais desempenhando funções ainda desconhecidas (Da Gama et al., 2008). Em 2007, Medeiros et al. testaram o potencial anti-incrustantes de quatro diferentes espécies de macroalgas contra a fixação do mexilhão Perna perna. Foi constatado que os extratos de Jania rubens e Bryothamnion seaforthii, ambas do filo Rhodophyta, popularmente conhecidas como algas vermelhas, apresentaram atividade anti-incrustante significativa, enquanto as outras duas espécies, Dictyopteris delicatula (Phaeophyta) e Heterosiphonia gibesii (Rhodophyta), não mostraram eficiência na inibição da fixação dos bissos do molusco.

Mais recentemente, Da Gama et al. (2008), também identificaram a eficiência de extratos de algas vermelhas na inibição da bioincrustação. Dos 68 extratos de algas marinhas coletadas na costa brasileira, $55 \%$ dos extratos ativos (moderada ou forte inibição da incrustação) eram representados pelas algas vermelhas, seguidas pelas algas pardas (14\%). As algas verdes, também testadas, não apresentaram atividade antiincrustante forte.
Em ambos os estudos não foi observada uma mortalidade significativa entre os organismos testados, reforçando a ideia de que os produtos naturais de origem marinha podem, futuramente, ser utilizados como alternativas "ecologicamente corretas" em substituição aos compostos anti-incrustantes empregados atualmente.

Algumas bactérias, assim como as algas marinhas, também produzem metabólitos secundários que agem prevenindo o estabelecimento de outros organismos incrustantes. Alguns destes compostos já foram isolados e identificados, como: ácido fenazina-1-carboxílico, 1-hidróxido fenazina, 2-n-heptil-4-hidroquinona, 2-n-nonil-4-hidroquinona e ácido piolípico extraídos de cultura de Pseudomonas sp. (Burgess et al., 2003).

Além desses metabólitos secundários, também foram propostos outros meios igualmente eficazes no processo de inibição da bioincrustação, como a utilização de enzimas e substâncias sintéticas que interfiram no estabelecimento de organismos incrustantes. As enzimas podem afetar a fixação e adesão de quatro diferentes maneiras: agindo sobre as substâncias adesivas dos microorganismos; degradando os polímeros que constituem a matriz do biofilme, gerado durante o processo de bioincrustação; catalisando a liberação de compostos antiincrustantes dos revestimentos dos cascos das embarcações; e, por último, interferindo na comunicação intercelular durante a colonização da superfície (Kristensen et al., 2008).

A utilização da substância sintética medetomidina, um agonista $\alpha 2$-adrenérgico, tem sido proposta como um potencial agente anti-incrustante devido a suas propriedades biocidas (Krang \& Dahlström, 2006). Receptores adrenérgicos não são encontrados em invertebrados, mas interações com receptores farmacologicamente similares aos receptores $\alpha 2$-adrenérgicos de vertebrados têm sido sugeridas para a inibição da fixação de larvas de cracas (Dahlström et al., 2005).

No entanto, Krang e Dahlström (2006) observaram que a medetomidina pode interferir no comportamento reprodutivo de Corophium volutator, uma espécie não-alvo de crustáceo. Machos expostos a essa substância reduziram a atividade de busca por fêmeas, induzida por feromônios liberados por estas. O resultado reforça a necessidade de futuras investigações acerca dos efeitos desse composto sobre espécies nãoalvo e os cuidados que se devem tomar antes da produção e comercialização de qualquer produto que possa oferecer potenciais riscos à biota aquática.

\section{CONSIDERAÇÕES FINAIS}

Os primeiros indícios da contaminação do ambiente marinho por compostos organoestânicos foram observados no início dos anos 80. A partir de então, as preocupações quanto ao uso de produtos contendo estes biocidas levaram alguns países a restringir a sua comercialização, resultando no banimento completo, em escala global, em janeiro de 2008.

Dentre os diversos efeitos associados à ação dos compostos organoestânicos sobre a biota aquática, destaca- 
se a disrupção endócrina em gastrópodes, envolvendo o desenvolvimento de caracteres sexuais masculinos em fêmeas destes animais, fenômeno conhecido como imposex. Embora as regulamentações para a utilização de tintas anti-incrustantes à base de estanho tenha repercutido em uma diminuição nos níveis desses compostos no meio aquático, ainda há registros da ocorrência destes compostos em altas concentrações, inclusive em áreas remotas como a Antártida e a Grande Barreira de Corais da Austrália (Negri \& Marshall, 2009). Além disso, os produtos atualmente comercializados também apresentam efeitos tóxicos aos organismos.

O desenvolvimento de sistemas anti-incrustantes naturais tem sido uma das metas de alguns grupos de pesquisa nos últimos anos. No entanto, os resultados desses estudos ainda são escassos e requerem mais investigações, necessitando de um incentivo maior por parte das autoridades competentes.

\section{REFERÊNCIAS}

AGARWAL S., AGGARWAL S.G., SINGH P., 2005, Quantification of ziram and zineb residues in fog-water samples. Talanta. 65 : 104-110. http://dx.doi.org/10.1016/j.talanta.2004.05.041.

ALMEIDA E., DIAMANTINO T.C., DE SOUSA O., 2007a, Marine paints: The particular case of antifouling paints. Prog. Org. Coat. 59: 2-20. http://dx.doi.org/10.1016/j.porgcoat.2007.01.017.

ALMEIDA E., DIAMANTINO T., DE SOUSA O., 2007b, Breve história das tintas antivegetativas. Corros. Prot. Mater. 26: 6-12.

ALZIEU C., 2000, Environmental impact of TBT: the French experience. Sci. Total Environ. 258: 99-102. http://dx.doi. org/10.1016/S0048-9697(00)00510-6.

ANTIZAR-LADISLAU B., 2008, Environmental levels, toxicity and human exposure to tributyltin (TBT)-contaminated marine environment. A review. Environ. Int. 34: 292-308. http://dx.doi. org/10.1016/j.envint.2007.09.005.

BAYER CROPSCIENCE, 2008, Material Safety Data Sheet.

BIGATTI G., PRIMOST M.A., CLEDÓN M., AVERBUJ A., THEOBALD N., GERWINSKI W., ARNTZ W., MORRICONI E., PENCHASZADEH P.E., 2009, Biomonitoring of TBT contamination and imposex incidence along $4700 \mathrm{~km}$ of Argentinean shoreline (SW Atlantic: From $38 \mathrm{~S}$ to $54 \mathrm{~S}$ ). Mar. Pollut. Bull. 58: 695-701. http://dx.doi.org/10.1016/j. marpolbul.2009.01.001.

BLABER S.J.M., 1970, The occurrence of a penis-like outgrowth behind the right tentacle in spent females of (Nucella lapillus, L). J. Mollus. Stud. 39: 231-233.

BURGESS J.G., BOYD K.G., ARMSTRONG E., JIANG Z., YAN L., BERGGREN M. et al., 2003, The Development of a marine natural product-based antifouling paint. Biofouling. 19: 197-205. http://dx.doi.org/10.1080/0892701031000061778.

CASTRO I.B., MATTHEWS-CASCON H., FERNANDEZ M.A., 2000, Imposex em Thais haemastoma (Linnaeus, 1767) (Mollusca: Gastropoda) uma indicação da contaminação por organoestânicos na costa do município de Fortaleza - Ceará Brasil. Arq. Ciên. Mar. 33: 143-148.

CASTRO I.B., MEIRELLES C.A.O., MATTHEWS-CASCON H., FERNANDEZ M.A., 2004, Thais (Stramonita) rustica (Lamarck, 1822) (Mollusca:Gastropoda:Thaididae), a potential bioindicador of contamination by organotin Northeast Brazil. Braz. J. Oceanogr. 52(2): 135-139. http://dx.doi.org/10.1590/ s1679-87592004000200005.
CASTRO I.B., BRAGA A.R.C., ROCHA-BARREIRA C.A., 2005, Altos índices de imposex em Stramonita rústica (Mollusca: Gastropoda) em áreas portuárias dos estados de Alagoas e Sergipe, Brasil. Tropical Oceanography. 33(2): 121-128.

CASTRO I.B., BENVENUTTI C.E., FILLMANN G., 2007, Preliminary appraisal of imposex in areas under the influence of southern Brazilian harbours. J. Braz. Soc. Ecotoxicol. 2(1): 73-79.

CASTRO I.B., MEIRELLES C.A.O., MATTHEWS-CASCON H., ROCHA-BARREIRA C.A., PENCHASZADEH P., BIGATTI G., 2008, Imposex in endemic volutid from Northeast Brazil (Mollusca:Gastropoda). Braz. Arch. Biol. Techn. 51(5): 10651069. http://dx.doi.org/ 10.1590/s1516-89132008000500024.

CEULEMANS M., SLAETS S., ADAMS F., 1998, Speciation of organotin in environmental sediment samples. Talanta. 46: 395405. http://dx.doi.org/10.1016/S0039-9140(97)00403-7.

CHAMBERS L.D., STOKES K.R., WALSH F.C., WOOD R.J.K., 2006, Modern approaches to marine antifouling coatings. Surf. Coat. Tech. 201: 3642-3652. http://dx.doi.org/10.1016/j. surfcoat.2006.08.129.

CHAMP M.A. \& LOWENSTEIN F.L., 1987, The Dilemma of High Technology Antifouling Paints. Oceanus. 30: 69-77.

CHOU A.P., MAIDMENT N., KLINTENBERG R., CASIDA J.E., LI S., FITZMAURICE A.G., FERNAGUT P., MORTAZAVI F., CHESSELET M., BRONSTEIN J.M., 2008, Ziram causes dopaminergic cell damage by inhibiting E1 ligase of the proteasome. J. Biol. Chem. 283(50): 34696-34703. http://dx.doi. org/10.1074/jbc.M802210200.

CIMA F., BRAGADIN M., BALLARIN L., 2008, Toxic effects of new antifouling compounds on tunicate haemocytes - I. SeaNine $211^{\mathrm{TM}}$ and chlorothalonil. Aquat. Toxicol. 86: 299-312. http://dx.doi.org/10.1016/j.aquatox.2007.11.010.

DA COSTA M.B., FERNANDEZ M.A., BARBIERO D.C., DE MELO F.T.V., OTEGUI M.B.P., FERREIRA B.S., 2008, First Record of imposex in Thais deltóidea (Lamark, 1822) (Mollusca, Gastropoda, Thaididae) in Vitória, ES, Brazil. Braz. J. Oceanogr. 56(2): 145-148. http://dx.doi.org/10.1590/s167987592008000200007.

DA GAMA B.A.P., CARVALHO A.G.V., WEIDNER K., SOARES A.R., COUTINHO R., FLEURY B.G. et al., 2008, Antifouling activity of natural products from Brazilian seaweeds. Bot. Mar. 51: 191-201. doi/10.1515/bot.2008.027.

DAHLSTRÖMM., LINDGRENF., BERNTSSONK., SJÖGRENM., MARTENSSON L.G.E., JONSSON P.R. et al., 2005, Evidence for different pharmacological targets for imidazoline compounds inhibiting settlement of the barnacle Balanus improvisus. J. Exp. Zool. 303(A): 551-562. doi:10.1002/jez.a.163.

DOS SANTOS D.M., 2008, Compostos organoestânicos no material particulado em suspensão e sedimentos superficiais no eixo lesteoeste do complexo estuarino de Paranaguá, PR. Dissertação, Universidade Federal do Paraná, Pontal do Paraná.

FELIZZOLA J.F., 2005, Especiação de Compostos Butílicos de Estanho em Sedimentos Superficiais da Baía de Todos os Santos. Dissertação, Pontifícia Universidade Católica do Rio de Janeiro, Rio de Janeiro.

FÉRAL C., 1974, Etude comparée dês populations d'Ocenebra erinacea (L.) de Granville et d'Arcachon. Haliotis. 4: 129-134.

FERNANDEZM.A.,LIMAVERDEA.M., CASTROI.B., ALMEIDA A.C.M., 2002, Occurrence of imposex in Thais haemastoma: possible evidence of environmental contamination derived from organotin compounds in Rio de Janeiro and Fortaleza, Brazil. Cad. Saúde Pública. 18(2): 463-476. http://dx.doi.org/10.1590/ S0102-311X2002000200011.

FERNANDEZ M.A., WAGENER A.L.R., LIMAVERDE A.M., SCOFIELD A.L., PINHEIRO F.M., RODRIGUES E., 2005, Imposex and surface sediment speciation: a combined approach to evaluate organotin contamination in Guanabara Bay, Rio de 
Janeiro, Brazil. Mar. Environ. Res. 59: 435-452. http://dx.doi. org/10.1016/j.marenvres.2004.07.001.

GADD G.M., 2000, Microbial interactions with tributyltin compounds: detoxification, accumulation, and environmental fate. Sci. Total Environ. 258: 119-127. http://dx.doi.org/10.1016/ S0048-9697(00)00512-X.

GIBBS P.E., 1993, A male genital defect in the dogwhelk Nucella lapillus (Neogastropoda), favoring the survival of a population in a TBT-pulluted area. J. Mar. Biol. Assoc. U.K. 73(3): 667-678. http://dx.doi.org/10.1017/S0025315400033208.

GODOI A.F.L., FAVORETO R., SANTIAGO-SILVA M., 2003, Contaminação ambiental por compostos organoestânicos. Quím. Nova. 26(5): 708-716. http://dx.doi.org/10.1590/S010040422003000500015.

GRÜN F., WATANABE H., ZAMANIAN Z., MAEDA L., ARIMA K., CUBACHA R. et al., 2006, Endocrine-disrupting organotin compounds are potent inducers of adipogenesis in vertebrates. Mol. Endocrinol. 20(9): 2141-2155. http://dx.doi.org/10.1210/ me.2005-0367.

HALL J.R.L.W., KILLEN W.D., ANDERSON R.D., BALCOMB R., GARDINALI P., 2009, Ecological risk of Irgarol 1051 and its major metabolite in coastal California marinas and references areas. Mar. Pollut. Bull. 58: 702-710. http://dx.doi.org/10.1016/j. marpolbul.2008.12.019.

HAMWIJK C., SCHOUTEN A., FOEKEMA E.M., RAVENSBERG J.C., COLLOMBON M.T., SCHMIDT K., KUGLER M., 2005, Monitoring of the booster biocide dichlofluanid in water and marine sediment of Greek marinas. Chemosphere. 60: 13161324. http://dx.doi.org/10.1016/j.chemosphere.2005.01.072.

HAN M.S., SHIN K., KIM Y., KIM S., LEE T., KIM E., RYU S.H., SUH P., 2003, Thiram and Ziram stimulate non-selective cation channel and induce apoptosis in PC12 cells. Neurotoxicology. 24: 425-434. http://dx.doi.org/10.1016/S0161-813X(03)00013-5.

HEIDRICH D.D., STECKELBROECK S., KLINGMULLER D., 2001, Inhibition of human cytochrome P450 aromatase activity by butyltins. Steroids. 66: 763-769. http://dx.doi.org/10.1016/ S0039-128X(01)00108-8.

HOCH M., 2001, Organotin compounds in the environment an overview. Appl. Geochem. 16: 719-743. http://dx.doi. org/10.1016/S0883-2927(00)00067-6.

HORIGUCHI T., KOJIMA M., HAMADA F., KAJIKAWA A., SHIRAISHI H, MORITA M. et al., 2006, Impact of Tributyltin and Triphenyltin on Ivory Shell (Babylonia japonica) Populations. Environ. Health Persp. 114: 13-19. http://dx.doi.org/10.1289/ ehp.8047.

HOUSTON R.S., 1971, Reproductive biology of Thais emarginata (Deshayes, 1839) and Thais canaliculata (Duclos, 1832). Veliger. 13: $348-357$.

HUGGETT R.J., UNGER M.A., SELIGMEN P.F., VALKIRS A.O., 1992, The marine biocide tributyltin. Environ. Sci. Technol. 26: 232-237. http://dx.doi.org/10.1021/es00026a001.

ICOMIA - International Council of Marine Industry Associations, 2006, Factsheet on copper-based antifouling.

JACOBSON A.H. \& WILLIAMS T.M., 2000, The environmental fate of isothiazolone biocides. Chim. Oggi. 18: 105-108.

JACOBSON AH \& WILLINGHAM G.L., 2000, Sea-Nine antifouling: an environmentally acceptable alternative to organotin antifoulants. Sci. Total Environ. 258: 103-110. http:// dx.doi.org/10.1016/S0048-9697(00)00511-8.

JOHNSON A., CAREW E., SLOMAN K.A., 2007, The effects of copper on the morphological and functional development of zebrafish embryos. Aquat. Toxicol. 84: 431-438. http://dx.doi. org/10.1016/j.aquatox.2007.07.003.
KANNAN K., FALANDYSZ J., 1997, Butyltin residues in sediment, fish, fish-eating birds, harbour porpoise and human tissues from the Polish coast of the Baltic Sea. Mar. Pollut. Bull. 34(3): 203207. http://dx.doi.org/10.1016/S0025-326(96)00146-4.

KATRANITSAS A., CASTRITSI-CATHARIOS J., PERSOONE G., 2003, The effect of a copper-based antifouling paint on mortality and enzymatic activity of non-target marine organism. Mar. Pollut. Bull. 46: 1491-1494. http://dx.doi.org/10.1016/ S0025-326X(03)00253-4.

KETATA I., DENIER X., HAMZA-CHAFFAI A., MINIER C., 2008, Endocrine-related reproductive effects in molluscs. Comp. Biochem. Physiol. 147(C): 261-270. http://dx.doi.org/10.1016/j. cbpc.2007.11.007.

KHANDEPARKER L. \& ANIL A.C., 2007, Underwater adhesion: The barnacle way. Int. J. Adhes. Adhes. 27: 165-172. http:// dx.doi.org/10.1016/j.ijadhadh.2006.03.004.

KOBAYASHI N. \& OKAMURA H., 2002, Effects of new antifouling compounds on the development of sea urchin. Mar. Pollut. Bull. 44: 748-751. http://dx.doi.org/10.1016/S0025326X(02)00052-8.

KONSTANTINOU I.K. \& ALBANIS T.A., 2004, Worldwide occurrence and effects of antifouling paint booster biocides in the aquatic environment: a review. Environ. Int. 30: 235-248. http://dx.doi.org/10.1016/S0160-4120(03)00176-4.

KRANG A. \& DAHLSTRÖM M., 2006, Effects of a candidate antifouling compound (medetomidine) on pheromone induced mate search in the amphipod Corophium volutator. Mar. Pollut. Bull. 52: 1776-1783. http://dx.doi.org/10.1016/j. marpolbul.2006.09.015.

KRISTENSEN J.B., MEYER R.L., LAURSEN B.S., SHIPOVSKOV S., BESENBACHER F., POULSEN C.H., 2008, Antifouling enzymes and the biochemistry of marine settlement. Biotechnol. Adv. 26: 471-481. http://dx.doi.org/10.1016/j. biotcchadv.2008.05.005.

LAMOREE M.H., SWART C.P., VAN DER HORST A., VAN HATTUM B., 2002, Determination of diuron and the antifouling paint biocide Irgarol 1051 in Dutch marinas and coastal waters. J. Chromatogr. 970(A): 183-190. http://dx.doi.org/10.1016/ S0021-9673(02)00878-6.

LEUNG K.M.Y., KWONG R.P.Y., NG W.C., HORIGUSHI T., QIU J.W., YANG R. et al., 2006, Ecological risk assessments of endocrine disrupting organotin compounds using marine neogastropods in Hong Kong. Chemosphere. 65: 922-938. http:// dx.doi.org/10.1016/j.chemosphere.2006.03.048.

LYSSIMACHOU A., BACHMANN J., PORTE C., 2008, Shortterm exposure to the organotin compound triphenyltin modulates esterified steroid levels in females of Marisa cornuarietis. Aquat. Toxicol. 89: 129-135. http://dx.doi.org/10.1016/j. aquatox.2008.06.009.

MAGUIRE R.J., TKACZ R.J., CHAU Y.K., BENGERT G.A., WONG P.T.S., 1986, Occurrence of organotin compounds in water and sediment in Canada. Chemosphere. 15: 253-274. http://dx.doi.org/10.1016/0045-6535(86)90020-2.

MARALDO K., DAHLLÖF I., 2004, Indirect estimation of degradation time for zinc pyrithione and copper pyrithione in seawater. Mar. Pollut. Bull. 48: 894-901. http://dx.doi. org/10.1016/j.marpolbul.2003.11.013.

MEDEIROS H.E., DA GAMA B.A.P., GALLERANI G., 2007, Antifouling activity of seaweed extracts from Guarujá, São Paulo, Brazil. Braz. J. Oceanogr. 55(4): 257-264. http://dx.doi. org/10.1590/S1679-87592007000400003.

NAKANISHI T., 2008, Endocrine disruption induced by organotin compounds; organotins function as a powerful agonist for nuclear 
receptors rather than an aromatase inhibitor. J. Toxicol. Sci. 33: 269-276. http://dx.doi.org/10.2131/jts.33.269.

NEGRI A. \& MARSHALL P., 2009, TBT contamination of remote marine environments: Ship groundings and ice-breakers as sources of organotins in the Great Barrier Reef and Antarctica. J. Environ. Manage. 90: S31-S40. http://dx.doi.org/10.1016/j. jenvman.2008.06.009.

NISHIKAWA J., MAMIYA S., KANAYAMA T., NISHIKAWA T., SHIRAISHI F., HORIGUCHI T., 2004, Involvement of the Retinoid X Receptor in the Development of Imposex Caused by Organotins in Gastropods. Environ. Sci. Technol. 38(23): 62716276. http://dx.doi.org/10.1021/es049593u.

NORMAM-23/DPC - Normas da Autoridade Marítima para o Controle de Sistemas Antiincrustantes Danosos em Embarcações, 2007, Marinha do Brasil - Diretoria de Portos e Costas.

OBERDÖSTER E., ROMANO J., MCCLELLAN-GREEN P., 2005, The Neuropeptide APGWamide as a Penis Morphogenic Factor (PMF) in Gastropod Mollusks. Integr. Comp. Biol. 45: 28-32. http://dx.doi.org/10.1093/icb/45.1.28.

OKAMURA H., 2002, Photodegradation of the antifouling compounds Irgarol 1051 and Diuron released from a commercial antifouling paint. Chemosphere. 48: 43-50. http://dx.doi. org/10.1016/S0045-6535(02)00025-5.

OMAE I., 2006, Chemistry and Fate of Organotin Antifouling Biocides in the Environment, pp. 17-50. In: Handbook of Environmental Chemistry. Berlin, Springer-Verlag, v. 5O. http:// dx.doi.org/ 10.1007/698_5_048.

PARKS R., DONNIER-MARECHAL M., FRICKERS P.E., TURNER A., READMAN J.W., 2010, Antifouling biocides in discarded marine paint particles. Mar. Pollut. Bull. http://dx.doi. org/ 10.1016/j.marpolbul.2010.03.022.

QUEIROZ L.R., CASTRO I.B., ROCHA-BARREIRA C.A., 2007, New Imposex Development Index (IDI) for Stramonita haemastoma (Mollusca: Muricidae): A Transplantation Experiment in the Brazilian Northeast. J. Braz. Soc. Ecotoxicol. 2(3): 249-256.

REICHELT-BRUSHETT A.J. \& HARRISON P.L., 2000, The effect of copper on the settlement success of larvae from the scleractinian coral Acropora tenuis. Mar. Pollut. Bull. 41: 385391. http://dx.doi.org/10.1016/S0025-326X(00)00131-4.

RÜDEL H., 2003, Case study: bioavailability of tin and tin compounds. Ecotox. Environ. Safe. 56: 180-189. http://dx.doi. org/10.1016/S0147-6513(03)00061-7.

SANTALLA R.P., 2008, Especiação de organoestânicos em matrizes ambientais por extracção sorptiva em barra de agitação e análise por cromatografia gasosa acoplada à espectrometria de massa. Dissertação, Universidade de Lisboa, Lisboa.

SAPHIER A.D. \& HOFFMANN T.C., 2005, Forecasting models to quantify three anthropogenic stresses on coral reefs from marine recreation: Anchor damage, diver contact and copper emission from antifouling paint. Mar. Pollut. Bull. 51: 590-598. http:// dx.doi.org/10.1016/j.marpolbul.2005.02.033.

SHADE W.D., HURT S.S., JACOBSON A.H., REINERT K.H., 1993, Ecological risk assessment of a novel marine antifouling. Am. Soc. Test. Mater. 1216: 381-407.

SHIMASAKI Y., KITANO T., OSHIMA Y., INOUE S., IMADA
N., HONJO T., 2003, Tributyltin causes masculinisation in fish. Environ. Toxicol. Chem. 22: 141-144. http://dx.doi.org/10.1002/ etc. 5620220118 .

SMITH B.S., 1971, Sexuality in the American mud snail, Nassarius obsoletus Say. J. Mollus. Stud. 39: 377-378.

SOLONESKI S., REIGOSA M.A., LARRAMENDY M.L., 2003, Vitamin E prevents ethylene bis(dithiocarbamate) pesticide zinebinduced sister chromatid exchange in Chinese hamster ovary cells. Mutagenesis. 18(6): 505-510. http://dx.doi.org/10.1093/ mutage/geg026.

SRINAVASAN M. \& SWAIN G.W., 2007, Managing the use of copper-based antifouling paints. Environ. Manage. 39: 423-441. http://dx.doi.org/10.1007/s00267-005-0030-8

TAKAHASHI K., 2009, Release rate of biocide from antifouling paints, pp. 3-22. In: T. Arai, H. Harino, M. Ohji, W.J. Langston (eds.), Ecotoxicology of Antifouling Biocides. Tokyo, Springer, $437 \mathrm{p}$.

THOMAS K.V., 2001, The environmental fate and behaviour of antifouling paint booster biocides: a review. Biofouling. 17: 7386. http://dx.doi.org/10.1080/08927010109378466.

TOLOSA I., READMAN J.W., BLAEVOET A., GHILINI S., BARTOCCI J., HORVAT M., 1996, Contamination of Mediterranean (Côte d'Azur) coastal waters by organotins and Irgarol 1051 used in antifouling paints. Mar. Pollut. Bull. 32(4): 335-341. http://dx.doi.org/10.1016/0025-326X(96)00013-6.

TURLEY P.A, FENN R.J., RITTER J.C., 2000, Pyrithiones as antifoulants: environmental chemistry and preliminary risk assessment. Biofouling. 15: 175-182. http://dx.doi. org/10.1080/08927010009386308.

UCP - Universal Crop Protection Ltd., 2008, Material Safety Data Sheet.

VAN WEZEL A.P., VAN VLAARDINGEN P., 2004, Environmental risk limits for antifouling substances. Aquat. Toxicol. 66: 427444. http://dx.doi.org/10.1016/j.aquatox.2003.11.003.

VOULVOULIS N., SCRIMSHAW M.D., LESTER J.N., 2000, Ocurrence of four biocides utilized in antifouling paints, as alternatives to organotin compounds, in waters and sediments of a commercial estuary in the UK. Mar. Pollut. Bull. 40: 938-946. http://dx.doi.org/10.1016/S0025-326X(00)00034-5.

WATERMANN B.T., DAEHNE B., SIEVERS S., DANNENBERG R., OVERBEKE J.C., KLIJNSTRA J.W., HEEMKEN O., 2005, Bioassays and selected chemical analysis of biocide-free antifouling coatings. Chemosphere. 60: 1530-1541. http://dx.doi. org/10.1016/j.chemosphere.2005.02.066.

WHALEN M.M., LOGANATHAN B.G., KANNAN K., 1999, Immunotoxicity of environmentally relevant concentrations of butyltins on human natural killer cells in vitro. Environ. Res. 81: 108-116. http://dx.doi.org/10.1006/enrs.1999.3968.

WHALEN M.M., HARIHARAN S., LOGANATHAN B.G., 2000, Phenyltin inhibition of the cytotoxic function of human natural killer cells. Environ. Res. 84: 162-169. http://dx.doi.org/10.1006/ enrs.2000.4083.

WHOI - Woods Hole Oceanographic Institute, 1952, The Prevention of Fouling with Toxics, pp. 241-263. In: Marine Fouling and Its Prevention. Menasha, George Banta Publishing Co. 